\title{
A New Paradigm for STEM Learning and Identity in English Language Learners: Science Translation as Interdisciplinary, Multi-Modal Inquiry
}

Dr. Patricia Gray, UNC-Greensboro, Amy Germuth, EvalWorks LLC, Jessica MacNair, Cabarrus County School System, Claire Simpson, UNCGreensboro, Sarah Sowa, Central Piedmont Community College, Nancy van Duin, Guilford County School System \& Claudia Walker, Guilford County School System

\begin{abstract}
This two-year case study examined multi-modal, interdisciplinary approaches to engage both immigrant English Second Language (ESL) and English Language Learners (ELL) in STEM (science, technology, engineering, math) learning and to build STEM identity and self-efficacy. Leveraging innate abilities, multiple intelligences, and self-identified interests, children in Grades 3 through 8, new to America and STEM, became inquiry-based researchers of sound-making, soundscapes, and nonverbal communication systems in diverse species including human music-making using technology, analysis, communication research, and observation skills. Using generative and lateral thinking methodology for science translation, interdisciplinary methods, and team-based learning, the students demonstrated increased STEM interest, STEM learning, and STEM skill sets while developing self-efficacy as STEM learners and communicators.
\end{abstract}

Key Words: science education, immigrant, English Language Learners (ELL), multi-modal learning, interdisciplinary, learner-centered, knowledge translation.

\section{Background}

$\mathrm{t}$ is widely observed that despite many efforts by researchers, new policies and programs, educational equity for underrepresented ethnic minority students (URMs) in the United States is an elusive and mostly failed effort (Chemers et al, 2011, p. 442). It is further acknowledged that "Science education has largely been unsuccessful in reaching ELL (English Language Learner), Latino, Native American, African American and other non-mainstream student groups, who remain underrepresented in the field of science" (Meyer \& Crawford, 2011). Immigrant children represent nine percent of all U.S. public school students, 4.6 million of which are ELLs whose numbers are growing (DOE, 2015). These students face substantive barriers to full participation in science, technology, engineering, math (STEM) education, often living in intensely segregated, low-income communities with underresourced schools, and centered in families where parents may have little formal education or familiarity with US educational systems and career pathways (Crosnoe \& Turley, 2011).

A growing body of research in the social sciences, psychology, and education suggests ways to counter these forces and to build inclusive pipelines for STEM participation in diverse populations. Common to these findings is the importance of 1) supporting these children's identity and belonging, which is developed through being recognized by oneself and others as capable, valuable, and competent in a given field (Carlone, Scott, \& Lowder, 2014; Luehmann, 2007; Buxton \& Provenzo, 2010), and 2) reevaluating learning environments and methods (Robinson \& Aronica, 2015; Meyer \& Crawford, 2011) in support of creating an authentic immigrant context for STEM knowledge construction and communication. Developing a productive STEM learner identity involves providing opportunities to develop and deepen STEM content understanding and practices, to contribute to a community of learners, and to develop a sense of selfefficacy as a STEM learner (Calabrese Barton \& Tan, 2010; Herrenkohl \& Mertl, 2010). Research in the learning sciences also stresses the importance of engaging student interest and participation through leveraging personal interests and histories (National Research Council, 2015). To broaden participation in STEM learning, it is essential that programs position students' interests, histories, and skills as assets, or "funds of knowledge" (Moje et al., 2004; Moll, Amanti, Neff, \& Gonzalez, 2009) - building blocks central to the purpose and activity of the program (Eisenhart, Finkel, \& Marion, 1996; Lemke, 2001).

There is much scholarship documenting culturally diverse and ELL youths' disenfranchisement from STEM disciplines (Bang \& Medin, 2010; Calabrese Barton, Tan, \& Rivet, 2008; Rahm, 2014; Thompson, 2014). Indeed, much of this research describes formal 
STEM education as "racialized" and "gendered," and contends that formal STEM education tends to marginalize the funds of knowledge and experiences that culturally diverse and ELL youth bring to STEM learning environments. Further, such environments may provide few "identity resources" (Nasir, 2012) for youth to enable them to take up new roles or responsibilities that position them as competent or developing experts (Bell et al., 2013). Hence, there is a great need to understand how STEM learning environments can broaden these marginalized youths' participation in STEM in ways that afford, rather than constrain, the range of available identity resources.

The current challenge to equip students with 21 st century skills includes the exploration of intersections among core subjects to prepare children for "the competitive, complex, and connected world they will inherit" (Partnership for 21st Century Skills, 2007, p. 2). An interdisciplinary approach provides students ways to develop more knowledge and skills and possess better mastery of the materials than discipline focused traditional programs (Bransford, 2000). Using funds of knowledge with inquiry-based learning, students can explore a trilateral collaboration in concepts, explanations, and learning outcomes that expand from collecting data and relevant information to include comparative learning, increase awareness of science as important to everyday life, and extend knowledge through translations of science into other spheres of knowing, intelligence, and communication.

We argue that if we are to expect students to apply "novel ideas to new situations," we must provide opportunities for students to practice science in many contexts (AAAS, 2009). Thus, this case study investigates how individual and collective STEM development can unfold in a cultural milieu that uses science as a framework to engage multiple intelligences in support of a collective, interdisciplinary learning culture. The study tracks how a STEM design grounded in multi-modal learning and science translation afford a STEM approach that is inventive, innovative, and meaningful for underrepresented ethnic minority children. By employing multi-modal, interdisciplinary methods with science translation, immigrant/ELL youth strengthened STEM interest and skills and increased STEM identity and STEM self-efficacy.

\section{The Study's Goals and Objectives}

During 2014-16, the Burroughs Wellcome Fund supported UBEATS (Universal BioMusic Education Achievement Tier in Science), an informal STEM program developed as an out-of-school intervention for immigrant children in Guilford County. (https://research.uncg.edu/spotlight/wild-music-festivalbrings-immigrant-children-to-stem/). The project, a collaboration of the University of North Carolina at
Greensboro's (UNCG) BioMusic Program and its Center for New North Carolinians (CNNC), the Greensboro Science Center (GSC), and the Guilford County School System, targeted children of immigrant families in the county, which has one of the fastest growing communities of new immigrants in the Southern United States; the majority coming from Central America and Southeast Asia, as well as Africa and the Middle East. (See Supplementary Materials).

Using an array of activities, the UBEATS student participants (Year 1: 50; Year 2: 81) in grades 3-8 studied music-making and animal communication systems as scientists. The program, led by UNCG Director of the BioMusic Program, professional teachers in STEM education and ELL, technology specialists, science center staff, a children's theatre professional (Year 2) and four immigrant high school student interns, created learning activities based on a BioMusic curriculum grounded in the National Education Standards (National Research Council, 1996). UBEATS programming was structured to include two annual one-week summer camps, each followed by a once-a-month three-hour club meeting over two academic years (AY) at the Greensboro Science Center (GSC). Student learning activities featured sonic communication in humans and other species, data collection of terrestrial and marine species, hands-on experiences with audio technology and analysis programs, and student research of families' signifying sounds from countries of origin.

UBEATS curriculum, content, and activities center on sonic communication systems and human music-making, an untapped or rarely employed resource for funds of knowledge. Based on BioMusic research (Gray, 2014), animal behavioral and communication systems, and multi-modal information processing, UBEATS science learning proceeded by examining sonic communication systems and music-making using comparative analysis, technology manipulation, and science translation. Because UBEATS defines sonic communication and music-making as a biotechnology, content and methods are designed to stimulate learners to explore sound-making as survival strategy, analogous music-like structures, and sound/time perception in themselves and other species, while exploring the evolutionary trail of communication systems in an array of acoustic environments. This approach enables children to use their innate musicality as a basic tool in discovering how animal communication relates to human music making, while enabling students to affirm habits of discovery and inquiry (Carrier, 2012). Thus, UBEATS STEM content reflects interdisciplinary, firsthand, multi-modal approaches to knowledge-building that are found to be hallmarks of powerful learning in formal and informal environments and key attributes of learning for preparation for the 21st century workforce (National Research Council, 2009, 2012, 2015). 
This Study investigated whether and how nontraditional STEM learning methods based in the exploration and production of communicative behaviors can promote and broaden STEM identity and STEM selfefficacy in English speaking immigrant and ELL children. Our work examined two broad questions:

1) Will using interdisciplinary cross-cutting BioMusic concepts and practices that exercise innate human musical capacities underlying environmental information processing, communication, and culture creation increase and improve the multiple domains deemed critical to STEM competence, identity, and self-efficacy?

2) Can science translation using practices grounded in both the arts and sciences enhance STEM identity and self-efficacy in immigrant/ELL youths?

\section{Cross-Cutting Content and Activities}

What is BioMusic? BioMusic is a multidisciplinary field - biology, animal communication, ethnomusicology, music theory, neuroscience, physics, bioacoustics, and evolutionary biology - that studies music's biological and cognitive elements to explore relationships and meaning-making in humans and nonhumans (Gray et al, 2001). BioMusic research focuses on meaning-making using auditory perception, including the semiosis of sound in the social environment, as well as commonalities of musical sounds in all species, in relations of sonic patterns, frequencies, rhythms, volume, structures, significance, and their role in biodiversity (Gray, 2015).

The UBEATS program content and activities, based on and elaborated from BioMusic curriculum developed with a National Science Foundation STEM education grant ("UBEATS," 2013) to the University of North Carolina-Greensboro (UNCG) and North Carolina State University's Kenan Fellows Program, engaged the students to:

- Explore aural non-verbal structured communicative behaviors in humans and other species;

- Participate in real-time activities/games that reveal how time, frequency, amplitude, and memory impact animal/human communication systems;

- Explore environmental acoustics in animal behavior, adaptation, and sustainability;

- Explore the musical brain as a neurological communication system;

- Explore relationships between animal communication behavior and physical properties of sound in diverse environments (soundscapes);
- Record local soundscapes and use sound analysis software;

- Utilize sound technology for data collection and for creative purposes;

- Explore innovative ways to use symbols to represent sound;

- Explore live animal husbandry and habitat requirements for real-time engagement;

- Provide STEM career events;

- Create Participation for families in STEM events;

- Present parent showcases;

- Design \& produce translations of artifacts that blend aspects of creative expression and youths' interactions with the natural world.

Specifically, this study looked to design ways to affect the significant impacts of cultural, economic, and developmental differences of immigrant/ ELLs while broadening and strengthening their goals, expectations, and future thinking. To address these, UBEATS developed learning activities in the second year that supported the translation of science knowledge as a strategy for immigrant/ELL learners to personalize STEM relevancy, convey their knowledge, and build selfefficacy. 


\section{Build Competence in STEM skills}

\section{Build Competence in using technology}

- Explore aural non-verbal structured communicative behaviors in humans and other species.

- Demonstrate that using symbols to capture auditory events enables students to develop STEM analytical skills and develop technology skills.

- Explore physics of sound and sound's physical/neurological processing pathways for multiple species.

- Explore the effects of environmental sonic changes, adaptations and behaviors that enable animals (including humans) to survive in changing habitats.

- Explore how animals meet their needs by using sonic behaviors in response to information received from the environment.

- Experience and practice audio research techniques and methods in controlled and wild environments.

- Offer opportunities to record sonic data in controlled and wild environments using diverse recording technologies (terrestrial and marine).

- Experience sound analysis techniques that use symbols to capture complex auditory events.

\section{Build STEM Identity}

- Offer multi-modal opportunities to develop STEM enthusiasm, conceptual and technical knowledge, and STEM identity.

- Offer students opportunities to engage in public presentations, to share their research and knowledge with their families, to build interest in STEM.

\section{Build STEM self-efficacy}

- Build on motivating and engaging children through their innate interests in music, animals, and team-based problem solving.

- Engage in the process of science translation.

- Focus on the physical properties of sound and how auditory systems are used for observation and sense-making.

- Provide access to live animals at the GSC to increase STEM knowledge about the role of sound in animal behaviors, sustainability, management, and biodiversity.

\section{Encourage Positive Attitudes toward STEM oriented behaviors and relevance}

- Provide research activities online, at home, and at UBEATS project sites that link systems thinking about sounds to children's everyday lives including humans, other animals, and sound environments.

\section{Increase Knowledge of STEM degree paths}

- Utilize opportunities in UBEATS lessons to provide students with pathways for sound-related degrees and future career information. (bioacoustics, acoustics, audiology, etc)

\section{Stimulate Interest in STEM Careers}

- Provide access to in-person early career STEM role models in diverse career paths.

- Provide experiences with new, non-verbal time/sound therapies and medical research. 


\section{Year One Methods}

YEAR ONE: UBEATS initial focus centered on the physical properties of sound and how the auditory system is used for observation and sense-making in humans and other species. Children used iPods, field recorders, a shotgun microphone, and a hydrophone to experience diverse sound environments and learn about ways that sound technology and sound analysis techniques provide research opportunities. Year One's activities at UBEATS camp, at a field trip to a state park, and at AY club meetings at the science center offered multiple opportunities to explore wild environments and animals using symbols to capture auditory events and enabled students to develop analytical and technology skills to link systems thinking about sounds of humans, other animals, and sound environments to their everyday lives. To increase STEM knowledge about the role of sound in biodiversity, the GSC provided access to their wide range of resources, including habitats of resident terrestrial and marine animals, enabling students to collect data, sound recordings, and observational details during changing seasons and environments.

Information about career paths and opportunities was provided by invited early career scientists in bioinformatics, wildlife preservation, and neuroscience, as well as animal caretakers at the GSC who gave in-person presentations at club meetings about the scope of their careers, educational arcs, and how sound is used in their field. Each speaker included detailed information about their personal progression from high school to higher education, and how and why they followed their career paths.

Building Family Involvement. UBEATS students and families received free annual passes to the GSC during Year One and Two to encourage family visits and to support students' interests beyond UBEATS planned learning activities. To enable greater family participation at annual capstone events (The Wild Music Festivals), immigrant community leaders greeted families, and free transportation and welcoming signage in 5 languages was provided. During each year's Wild Music Festival, participating children presented a special program in the GSC's OmniTheater for their families supported by multiple translators, provided an overview of their UBEATS activities, and concluded with a reception for the children and their families.
Student Documentaries. Four high school immigrant students (countries of origin: Liberia, Burma, Mexico, and Vietnam) served as mentors during Years One and Two, supporting learning activities and working with the UBEATS Learning Leaders. Working as a collaborative team and mentored by media professionals, they also designed and produced two annual Student

Documentaries that reflected their perspectives on the meaning and importance of UBEATS. They learned video production and editing techniques, interviewed key personnel, and shot additional video at community sites for each year's five-minute UBEATS documentary (UBEATS H.S. Student Mentors Documentary," 2015).

YEAR One - Capstone Event. The Wild Music Festival's (WMF) inclusion in the GSC's public offerings, provided ways for typical science museum visitors and families to learn about the children's UBEATS activities. Year One's WMF featured exhibits of students' recordings of GSC resident species with a site map of the recordings and an exhibit of audio samples based on the children's research of their family elders' memories of signifying sounds from their countries of origin. This also included a world map of specific countries represented. Participating students were tasked with explaining their STEM experiences and new knowledge to their families and the public.

YEAR ONE Results and Discussion: The first year's data, using surveys and focus groups following the opening camp experience, indicated the following:

- $\quad 91 \%$ of participants indicated increased interest in doing science;

- $85 \%$ indicated increased understanding of science's importance in their lives;

- $65 \%$ indicated science is a favorite subject;

- $82 \%$ indicated that they had good feelings about science;

- $78 \%$ indicated an increased recognition of science's importance in understanding the world;

- $82 \%$ reported increased interest in pursuing future science careers.

These results provided data that the project's educational approach using innovative multi-modal BioMusic curriculum as the primary learning stimulus presented a potent and important opportunity to increase immigrant students' interest in STEM learning. However, transitioning into the academic year's monthly 
club meetings presented challenges in continuity of attendance and therefore retention of conceptual learning. At the WMF, the planned opportunities for student sharing of STEM experiences and learning with the public and families were daunting. UBEATS staff found that most children retreated and preferred not to participate in this typical mode of scientific exchange. Girls, particularly, while enthusiastically engaged in UBEATS activities throughout Year One, avoided individual participation in public events at the WMF.

During UBEATS Year One of the AY club meetings, the Burroughs Wellcome Fund's standard student evaluation surveys were used and produced results asynchronous to the UBEATS staff observations. Questions were raised whether the standard survey data collected during the camps and monthly meetings captured an accurate picture of the children's learning, attitudes, and future thinking. After reviewing the language of the surveys in that context, UBEATS and BWF staff agreed that adjustments were needed for this population. Focus groups were increased and during surveys, staff could clarify meanings for the children, and that surveys may need to be read aloud to individual students, and as needed, to explain the intent of a question.

UBEATS staff Year One reviews of the children's progress identified perceived challenges to the children's future opportunities in STEM learning and careers. These included weak family support, lack of self-confidence, fission/fusion social behaviors undermining collaboration, and confusions about American cultural expectations and opportunities. [NOTE: 'fission/fusion', a concept from animal behavioral sciences, describes fluid/changing alliances that occur often and impact relationships and outcomes.] As noted in research of STEM education and culturally diverse immigrant communities:

In many societies, cultural norms prioritize respect for teachers and other adults as authoritative sources of knowledge. In other words, validity of knowledge is often based on the validity of its source, rather than the validity of knowledge claims. Children who are taught to respect the wisdom and authority of their elders may not be encouraged to question received knowledge in ways that are compatible with Western scientific practices or normative school science (Lee et al 2005).
While the UBEATS students journaled regularly, observations revealed that they preferred alternate, nonverbal means reliant on other intelligences to convey comprehension of their STEM learning. Drawing, gestures or dance movements, music-making, rapping, imitating sounds, and finding correlations to sound environments beyond UBEATS programming signaled untapped opportunities for these children to convey STEM learning.

Considering both the challenges and opportunities, UBEATS staff proposed a new learning design -science translation - as an intervention that could use the children's innate funds of knowledge with their acquired UBEATS STEM learning to counter the significant impacts of cultural, economic, and developmental differences. A science translation intervention employing children's theatre techniques was planned to assist with broadening and strengthening STEM learning, and support STEM identity and self-efficacy.

Year Two: Method and Rationale

YEAR TWO: Activities conducted in the second year utilized non-traditional STEM methods to engage UBEATS participants, comprised of both returning students and new arrivals, in thinking about, learning, and conveying STEM knowledge through the process of science translation. Using a targeted goal of producing a collaborative student-centered and created staged theatrical production to convey to families and the public the relevance and meaning of science, the study tested this method as a possible intervention to build STEM self-efficacy. By engaging student interest in using observation and listening skills, technology, and critical argument, students explored how to reinterpret science as valid story. This new approach leveraged Year One data showing that the UBEATS population, while interested in science $(81.8 \%)$, was also thinking about jobs in arts and entertainment (54.5\%). The data also showed that the children thought UBEATS helped them learn science better (63.6\%) and helped them feel better about learning science (72.7\%). However, more than half did not see science's relevance to everyday life (54.6\%). Thus, the planning for UBEATS Year Two summer camp and its successive AY club activities focused on developing an alternative pathway, the translation of science knowledge, to leverage creativity a critical aspect of science research- and provide multimodal opportunities for students of diverse cultural and 
ethnic backgrounds to personalize and express STEM learning and its relevancy while engaged in collaborative research.

\section{Year Two: Methods}

All of Year Two's learning activities centered on science translation as the impetus for student research activities, analytical thinking, and abstract planning. Building on the students' previous research of sound environments, animal husbandry and communication, they were tasked with creating, making, and presenting STEM concepts through the medium of puppetry. This active, learner-centered process employed a hands-on, makerspace approach that challenged students to examine scientific questions in detail, take and defend perspective, and make sense of science's impactful role on life.

We hypothesized that: 1) this generative process of science learning and translation could imbed a creative, collaborative, and maker approach to STEM learning; 2 ) the process of dynamic engagement among and between children could heighten scientific discourse that would deepen the STEM experience; and 3 ) the creative process of shared commitment to inquiry and collaboration, aligned with STEM knowledge creation, could develop a path to STEM self-efficacy.

The methodology focused on the children developing story lines to engage audiences in the science of three specific animal species, selected by the children from resident species at the GSC, that they had ongoing access to and had engaged with during Year One. Mentored by a children's theatre professional, the children focused their research of sound's impact on behavioral, communicative, and husbandry sciences as the basis for story creation, character development, sounds and sound tracks, costuming, scenery, and eventual performance. This process began during the 2015 summer camp and included a field trip to a professional puppet company where the children explored representation, allusion, and movement elements continued during UBEATS AY club meetings.

Children chose three species for story development and self-selected to join an animal's team 'tigers' or 'gibbons' or 'penguins' - making themselves experts, keeping detailed records of their research, and translating their knowledge of that animal to others. Learning activities were designed to support the authenticity of the developing story lines through questioning, debating, and reviewing scientific facts, and by increasing STEM knowledge of the three chosen species' behaviors, sound environments, conservation, and sustainability issues at the GSC and in the wild. Using observation skills, recording ambient and focused sounds, interviews with animal caretaking staff, and behind-exhibit observations, the students engaged as scientists to incorporate the complexity of sound's influence on animal behavior, survival, and well-being.

As students demonstrated little to no prior experience or knowledge of puppetry, drama, and mask work, students were first exposed to examples of each of these before being asked to apply their STEM learning outcomes. During the Year Two summer camp, students experimented with making puppets from every-day found objects. Working in small groups, they created simple story narratives using common household objects to explore how creative and imaginative work is accessible with no previous experience. Additionally, videos and pictures of professional productions combined with the summer camp's field trip to the professional puppet company provided students both the opportunity to experience professional manipulation of puppets and masks and first-hand physical manipulations with those objects. These activities further challenged the children to explore and compare the physics of movement in humans and animals while generating excitement about creating their own puppets and stories.

This translational process generated science narratives during UBEATS AY club meetings that revolved around two major drama-in-education practices: 1) create a student-centered environment that places students in-role as the expert; and 2) through exploratory generative activities, develop students' ideas, STEM knowledge and inquiry, and empathetic responses to an animal's behaviors, perspectives, and environmental needs.

This process requires a balance between input of both Learning Leader and students-a "flexible framework" that works to build on children's ideas. Such a supportive environment affords children the safety to "make a bridge for them[selves] between their own experiences of the world and the meaning of the drama, so that both insight and understanding arise from the activity." (O’Neil \& Lambers, 1982, p. 10). To this end, games and activities that leveled the power dynamic between Learning Leader and student 
simultaneously engaged and supported student cognition and its physical expression and encouraged inquiry-based learning to help students more accurately represent their animal's story, thereby building agency.

Second, the students' generative processes were supported and guided by the noted drama pedagogue, Constatin Stanislovski's, concept of what if - a phrase that is fundamental to all learning and that serves to jettison unnecessary imposed parameters or limitations. What if is used "as a lever to lift us out of the everyday life on to the plane of imagination." (Stanislavski, 1989, p. 59). Prompts, such as "what if 'you' [role playing as your animal] were to encounter a predator", were used to propel students into scenarios that engaged their knowledge of animal behavior and communication, and environmental issues while stimulating explorations of their animal's options and possible actions. Students generated scientifically grounded problems that their animal might encounter and the individual, group, and environmental options available to resolve them. They were challenged to define what their animal might 'want' using their STEM knowledge, and what was stopping their animal from achieving the objective. This process built the framework for the students' improvisations in-role as their animal.

Each group's narrative and major characters encompassed story-telling's basic protocols of antagonist, protagonist, and supporting characters. Through a guided design process, students began construction of representational puppets, masks, and habitats. Similar to the children's first introduction to puppetry, each animal group's characters and scenery began with simple materials that demonstrate puppetry's accessibility: cardboard, craft paint, and jersey knit fabric from recycled t-shirts. To increase family participation and interest, additional efforts at local community centers engaged parents and families in scene construction and costume building.

The role of sounds and sound-making in animal behavior, for survival and in environmental soundscapes, was the key provocative element for the narratives. Hence, the students focused on defining and representing the sounds that corresponded to their story. Each narrative's soundtrack was integrated as live Foley sounds made by the students, and as recordings that the students made of themselves, and/or through found sound files.
For the capstone performance of Year Two's Wild Music Festival, and to further emphasize the role of sound for the public and family members, audiences were asked to provide additional story-telling sounds cued by card prompts using icons instead of English words. Audience-provided sounds combined with the planned soundtracks to integrate environmental and animal noises critical to the telling of each story and were rehearsed with the audience just prior to each animal's puppet story performance.

Planning and Coordination of UBEATS Activities. The progression of the children's STEM learning around important information about their animals' sonic environments and behaviors with their evolving stories shaped the second-year's curriculum. The interdisciplinarity of the instructional team provided important, critical resources for the design and implementation of the programming and activities. The team's expertise in BioMusic, STEM education, theatre education, music education, ELL learning, and technology instruction helped shape resources in three areas - species education, story building and puppetry, and research of sound and/or music - anticipated and generated activities that supported the goals and objectives of the study's plan including the integrated scaffolding of unified learning sequences. Building on UBEATS first-year concepts and knowledge, relevant new information and activities were incorporated in the learning strategies to leverage conceptual learning across the continuum. Technology continued to play a significant role not only as a learning tool but with added importance for layering the sonic dimension into soundtracks for the puppet shows. Students used iPods to record the show's targeted species at the GSC and some of the sound effects eventually used in the shows. Additionally, sound recording apps were sourced to learn and review sound terminology, such as pitch/frequency and patterns, within the context of each animal's environment and communication frequency range of hearing and sound-making. Embedded multimedia played through a smart board helped students understand the complexity of their animal's habitat and the prey/predator relationships in those sonic habitats.

Throughout UBEATS programming, learning activities included building expertise in contextual knowledge and explicit but differentiated academic vocabulary used in different disciplines, specifically 
music, science, or technology. Student learning evolved collaboratively and competitively and was reinforced using appropriate scientific methods to inform all multimodal learning contexts. This process provided multiple but meaningful ways for diverse learners to participate and to convey STEM knowledge to peers and staff.

The final capstone event, the second Wild Music Festival, at the GSC featured two performances of three student-designed, student-created, and studentperformed puppet shows in a theater setting; one presented for their families and one for the public. By performing their science translations as a collaborative team, students invested in the quality and success of their team's storytelling and its performance, often advising one another about how to improve the performance while engaging in conversations about the meaning and importance of their animal's story.

\section{Discussion}

The second-year data suggest that the goals and objectives set for immigrant ESL and ELL children in STEM programming can be addressed in non-traditional, alternative ways. First, UBEATS wanted to know if these children developed STEM knowledge, expertise, and self-efficacy through the process. Results show (survey results in supplemental materials) that $60 \%$ to $80 \%$ acquired complex understandings of the integration of animal behavior, animal communication, environmental factors, and issues related to conservation and sustainability. Further, the children developed and relied on a suite of fundamental scientific process skills to address questions about their animal including:

- observation $75 \%$

- recording $66 \%$

- writing about $56 \%$

- reading about $50 \%$

- searching the internet $41 \%$

Finally, key impacts of UBEATS programming included positive attitudes:

- about science (77\% yes, a lot or yes, a little)

- about using science process skills (77\%)

- about interest in animals (82\%)

- interest in nature (88\%)

UBEATS experiences also changed:

- ideas about what scientists do (84\%)
- student perceptions of improved technology skills $(84 \%)$

All represent significant outcomes for building STEM self-efficacy.

\section{Conclusions}

This 2-year case study pursued alternative methods centered on employing diverse learning styles and multiple intelligences for culturally and linguistically diverse students. Specifically, non-traditional methods that exploit communicative behaviors served as a means to build STEM self-efficacy, identity, and learning in children who typically underperform in traditional classroom environments. In an innovative interdisciplinary and progressive cycle of learning activities, students acquired, used, and relied on STEM skills and academic vocabularies of multiple disciplines to realize a larger goal, a learning output they designed and performed for a valued audience. This learning design promotes students' communication of their understanding of STEM concepts while practicing skills and arguments used by scientists.

The larger arc and format for these learning outcomes capitalized on integrated, interdisciplinary multi-modal STEM content and a science translational process and performance. This approach leveraged nonverbal communication systems important to multiple fields of science, to the arts, and to sports but underrepresented in most academic learning environments. Its timeline allowed multiple accommodations for the Learning Leaders by providing: 1) adequate support for planning and preparation; 2) multiple sessions of cross-talk that developed an integrated team perspective.

For the children, self-efficacy in learning is understood to be central to enabling participation in the STEM pipeline. Research repeatedly shows that student self-efficacy, or a student's belief about their ability to be successful in a specific domain, is strongly related to "internal beliefs and experiences (that) combine to influence their ideas and expectations about their own capabilities with respect to STEM" (Dorsen et al, 2006). But recognizing oneself and others as capable, valuable, and competent in STEM remains an allusive outcome particularly for these children who typically receive disappointing performance feedback, experience educational inequities, grapple with cultural norms regarding expertise, and generally fade into the 
background or disappear when it comes to finding a voice in the formal or informal classroom (Betz \& Hackatt, 2006; Johnson-Ahorlu, 2012; Lent et al, 1994). The prevailing challenge remains how to stimulate young minds in ways that enable immigrant children to change preconceptions about their abilities and futures in STEM, while leveraging initial interests in science and curiosity about the world. To counter and restructure these cultural and conceptual patterns, UBEATS explored alternative methods and pathways for these children to think about, process, and participate in science learning.

Traditional approaches to STEM learning for immigrant students often channel activities grounded in vertical thinking outcomes - those associated with learning rules and right/wrong correlated choices. By suspending judgment and allowing multiple versions and rearrangements of information, the UBEATS students came to rely on their expertise, science knowledge and research, as well as their science processing skills while negotiating collaboration and innovation. This restructuring of the learning environment amplified opportunities to reinforce the value of inquiry on multiple levels in a re-imagined makerspace. Thus, by encouraging generative thinking, UBEATS students experimented with concepts and processes that challenge limiting parameters, categories, classifications, and labels, eventually finding new relevance in creating substantive translations of the science.

Learning research confirms multiple valid pathways to learn, think, and communicate science. The UBEATS intervention designed and tested a novel science translation method for diverse cultural and linguistic students using multiple intelligences in generative inquiry processes to expand how learning, thinking, and 'doing' science can take place. By enabling these children to develop a 'voice' within a STEM learning context, they controlled their success and science became fun and relevant to them and their families. The outcomes suggest that these positive experiences provide personal relevancy, increased STEM interest, and engaged future thinking about STEM - all critical elements for building self-efficacy in STEM.

\section{References}

Bang, M., Medin, D., Washinawatok, K., \& Chapman, S.
(2010). Innovations in culturally based science education through partnerships and community. In M. S. Khine \& M. I. Saleh (Eds.), New science of learning: Cognition, computers, and collaboration in education. New York, NY: Springer.

Bell, P., Bricker, L., Reeve, S., Zimmerman, H. T., \& Tzou, C. (2013). Discovering and supporting successful learning pathways of youth in and out of school: Accounting for the development of everyday expertise across settings. In LOST Opportunities (pp. 119-140). Springer Netherlands.

Betz, N. E., \& Hackett, G. (2006). Career self-efficacy theory: Back to the future. Journal of Career Assessment, 14(1), 3-11.

Bransford, J., National Research Council (U.S.)., \& National Research Council (U.S.). (2000). How people learn: Brain, mind, experience, and school. Washington, D.C: National Academy Press.

Buxton, C. \& Provenzo, E. (2010). Teaching Science in Elementary and Middle School: A Cognitive and Cultural Approach, 2nd edition. Thousand Oaks, CA: Sage Publications.

Calabrese Barton, A., \& Tan, E. (2010). "We Be Burnin!": Agency, Identity, and Science Learning. Journal of the learning sciences, 19(2), 187-229.

Carlone, H. B., Scott, C. M., \& Lowder, C. (2014). Becoming (less) scientific: A longitudinal study of students' identity work from elementary to middle school science. Journal of research in science teaching, 51(7), 836-869. doi:10.1002/tea.21150

Carrier, S., Wiebe, E. N., Gray, P., \& Teachout, D. (2011). BioMusic in the classroom: Interdisciplinary elementary science and music curriculum development. School Science and Mathematics, $111(8), 425-434$.

Chemers, M. M., Zurbriggen, E. L., Syed, M., Goza, B. K., \& Bearman, S. (2011). The role of efficacy and identity in science career commitment among underrepresented minority students. Journal of Social Issues, 67(3), 469-491.

Cheng, J. C. H., \& Monroe, M. C. (2012). Connection to 
Nature Children's Affective

Attitude Toward Nature. Environment and Behavior, 44(1), 31-49.

Crosnoe, R., \& Turley, R. N. L. (2011). K-12 educational outcomes of immigrant youth. The Future of Children, 21(1), 129-152.

Dawson, E. (2014). 'Not designed for us': How science museums and science centers socially exclude low-income, minority ethnic groups. Science education, 98(6), 981-1008. doi:10.1002/sce.21133

DOE 2015. National Center for Education Statistics https://nces.ed.gov/fastfacts/display.asp?id=96

Dorsen, J, Carlson B., Goodyear, L. (2006) Connecting Informal STEM Experiences to Career Choices: Identifying the Pathway. ITEST Learning Resource Center, retrieved from http://stelar.edc.org/sites/stelar.edc.org/files/ites tliteraturereview06.pdf

Dryfoos, J. \& Barkin, C. (2006). Adolescence: Growing Up in America Today. New York: Oxford University Press.

Eisenhart, M., Finkel, E., \& Marion, S. F. (1996). Creating the conditions for scientific literacy: A reexamination. American educational research journal, 33(2), 261-295.

Fadigan, K. A., \& Hammrich, P. L. (2004). A longitudinal study of the educational and career trajectories of female participants of an urban informal science education program. Journal of Research in Science Teaching, 41(8), 835-860.

Gallup Youth Survey. Washington DC: The Gallop Organization. 2004

Gray, P., Krause, B., Atema, J., Payne, R., Krumhansl, C., Baptista, L. (2001). The Music of Nature and the Nature of Music. Science Vol. 291, Issue 5501, pp. 52-54 DOI:10.1126/science.10.1126/SCIENCE.105696 0

Gray P (2014) What is BioMusic? Toward Understanding of Music-Making and Its Role in Life. Journal of Biomusical Engineering 2:e105. doi:10.4712/2090-2719.1000e105
Hackett, G., \& Byars, A. M. (1996). Social cognitive theory and the career development of African American women. The Career Development Quarterly, 44(4), 322340.

Herrenkohl, L. R., \& Mertl, V. (2010). How students come to be, know, and do: A case for a broad view of learning. New York: Cambridge University Press.

Johnson-Ahorlu, R. N. (2012). The academic opportunity gap: How racism and

stereotypes disrupt the education of African American undergraduates. Race Ethnicity and Education, 15(5), 633-652.

Krishnamurthi, A., Bevan, B., Colon, V., \& Rinehart, J. (2013). What afterschool STEM does best: How stakeholders describe youth learning outcomes. Afterschool matters(Fall), 42-49.

Large, E. W., \& Gray, P. M. (2015). Spontaneous tempo and rhythmic entrainment in a bonobo (Pan paniscus). Journal of Comparative Psychology, 129(4), 317.

Lee, O., Buxton, C., Lewis, S. and LeRoy, K. (2006), Science inquiry and student diversity: Enhanced abilities and continuing difficulties after an instructional intervention. J. Res. Sci. Teach., 43: 607-636. doi:10.1002/tea.20141

Lemke, J. L. (2001). Articulating communities: Sociocultural perspectives on science education. Journal of research in science teaching, 38(3), 296-316.

Lent, R. W., S. D. Brown, et al. (2005). Social Cognitive Predictors of Academic Interests and Goals in Engineering: Utility for women and students at historically Black universities. Journal of Counseling Psychology 52 (1): 84-92.

Luehmann, A. L. (2007). Identity development as a lens to science teacher preparation. Science education, 91(5), 822-839. Retrieved from http://search.ebscohost.com/login.aspx?direct=t rue \&db=ehh\&AN=26088334\&site =ehost-live

Meyer, X. \& Crawford, B.A. Cultural Studies of Science Education (2011) 6:525. doi:10.1007/s11422011-9318-6

Nasir, N. S., Rosebery, A. S., Warren, B., \& Lee, C. D. 
(2006). Learning as a cultural process: Achieving equity through diversity. In R. K. Sawyer (Ed.), The Cambridge handbook of the learning sciences (pp. 567-580). New York: Cambridge University Press.

National Research Council (Ed.). (1996). National science education standards. Washington, DC: National Academy Press.

National Research Council. (2009). Learning science in informal environments: People, places, and pursuits. Washington, DC: The National Academy Press.

National Research Council. (2012). Education for Life and Work: Developing Transferable Knowledge and Skills in the 21st Century. Retrieved from Washington DC: The National Academy Press

National Research Council. (2015). Identifying and Supporting Productive Programs in Out-ofSchool Settings. Washington, DC: The National Academy Press.

National Science Foundation (2015). Rebuilding the Mosaic: Fostering Research in the Social, Behavioral and Economic Sciences at the National Science Foundation in the Next Decade. Publication Number: NSF 11-086

O'Neil, C., Lambert, A. (1982). Drama Structures: A Practical Handbook for Teachers. Portsmouth, $\mathrm{NH}$ : Heinemann. Partnership for 21st Century Skills, (2007). e-paper retrieved from: http://www.p21.org/storage/documents/21st_C entury_Skills_Assessment_e-paper.pdf

Roberts, D. F., Henriksen, L., Christenson, P. G. (1999). Substance use in popular movies and music. Rockville, MD: Drug Policy Information Clearinghouse (ERIC Document Reproduction Service No. ED449404).

Robinson, K., Aronica, L. (2015). Creative Schools. New York: Viking.

Roe, K. (1996). Music and identity among European youth: Music as communication.

In P. Rutten (Ed.), Music in Europe, part II: Music, culture and society in Europe (pp. 85-97). Brussels: European Music Office.

Rosebery, A. S., Ogonowski, M., DiSchino, M., \&
Warren, B. (2010). "The coat traps all your body heat": Heterogeneity as fundamental to learning. Journal of the learning sciences, 19(3), 322-357.

Stanislavski, C. (1989). An Actor Prepares (E.R. Hapgood, Trans.). New York, NY: Routledge.

UBEATS Curriculum. (2013).

https://ubeats.uncg.edu/curriculum-downloads/

UBEATS High School Student Mentors produced Documentaries: https://ubeats.uncg.edu/documentary/

\section{About the Authors}

Dr. Pat Gray directs UNCG's BioMusic Research Initiative. Her latest project is UBEATS, a program that brings students to STEM through a focus on music and nature.

Amy Germuth is the Founder and President of EvalWorks.

Jessica MacNair is a Middle School Music Teacher with the Cabarrus County School System.

Claire Simpson is an MFA Graduate, Theatre for Youth UNC-Greensboro.

Sarah Sowa is a Library Specialist at Central Piedmont Community College.

Nancy van Duin is an ESOL Teacher at Falkener Elementary with the Guilford County School System.

Claudia Walker, NBCT, is a fifth-grade STEM Teacher with the Guilford County School System.

\section{Supplementary Materials Include:}

Participant Surveys, Years $1 \& 2$

Survey Results

Figure 1. Participants by Country of Origin

Figure 2. Participants by Gender

Figure 3. Participants by Grade Level 
A New Paradigm for STEM Learning and Identity in Young Immigrant and English Language Learners: Science Translation As Interdisciplinary, MultiModal Inquiry

\section{SUPPLEMENTAL MATERIAL}

1. Surveys Results - Year 2

\section{Findings from Survey Spring 2016}

Figure 1: Percentage of Students Who Reported Engaging in Specific Science Behaviors in Relation to the Animal They Studied

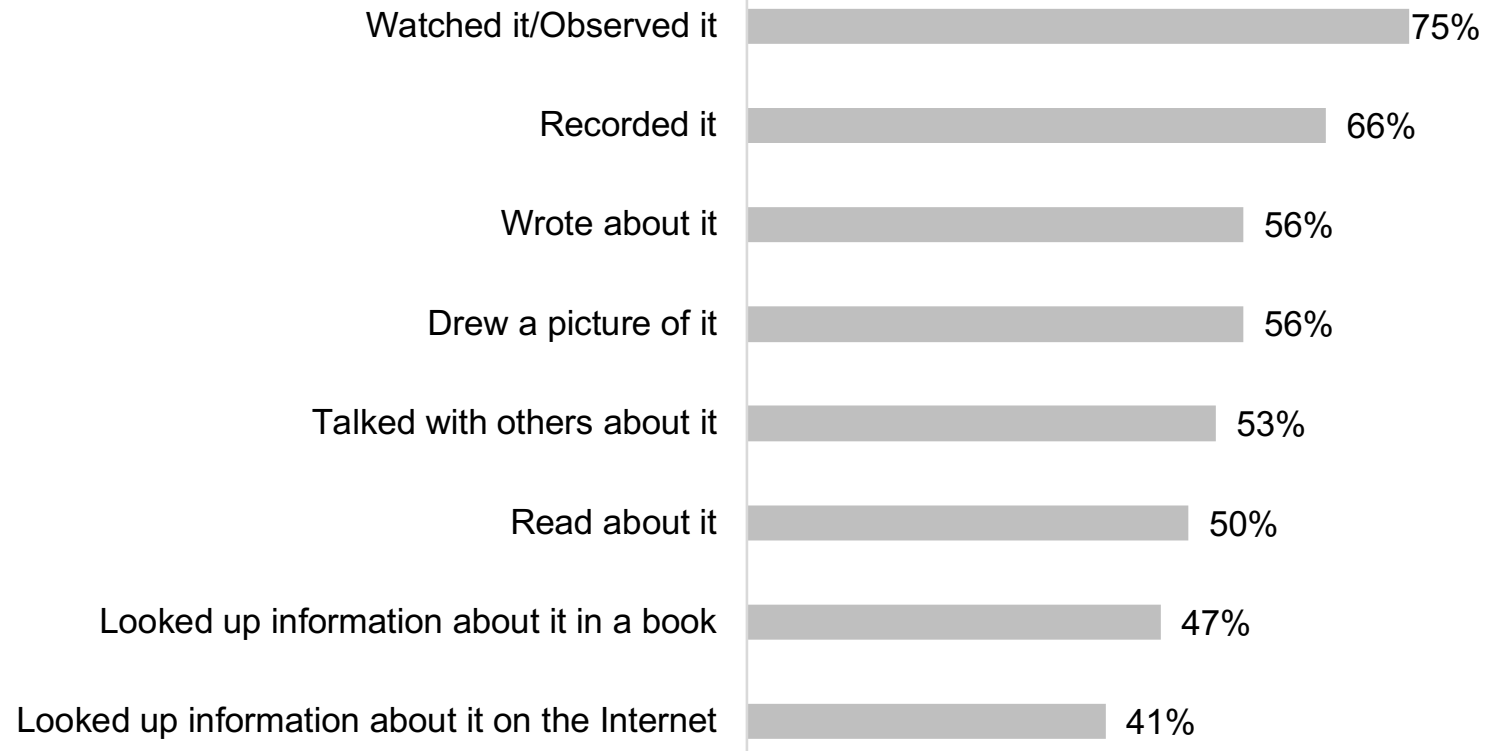

Figure 2: Students' Self-Identification of Their Knowledge Level of Their Animal Relative to Their Friends Not at UBEATS

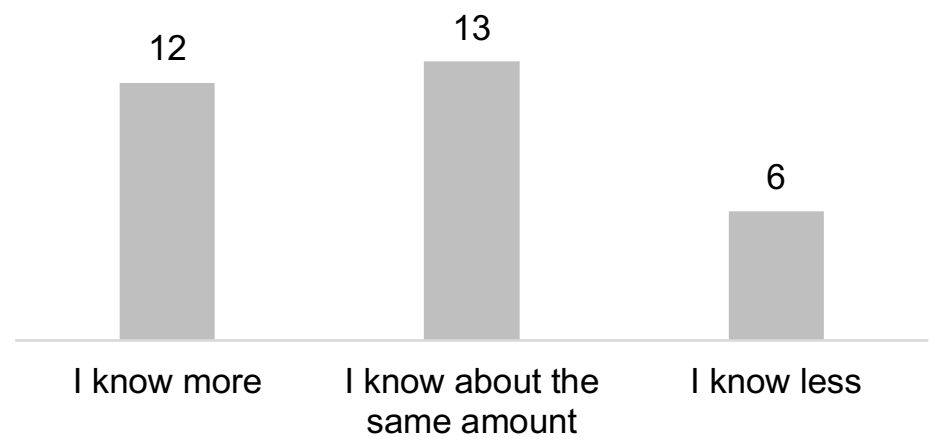




\section{A New Paradigm for STEM Learning and Identity in Young Immigrant and English Language Learners: Science Translation As Interdisciplinary, Multi- Modal Inquiry}

\section{Figure 3: Degree to Which Students Indicated That Being a Part of UBEATS Had the Following Impacts}

[Scale: Yes - a lot (3), Yes - a little (2), Not really (1)]

Helped you see that some scientists study animals as a living?

Increased your interests in animals?

Helped you better understand what scientists do?

Increased your interest in nature?

Increased your observation skills?

Increased your interest in science?

Increased your skills using technology?

Changed your ideas about what scientists do?

Made you think that being a scientist would be fun? 
A New Paradigm for STEM Learning and Identity in Young Immigrant and English Language Learners: Science Translation As Interdisciplinary, MultiModal Inquiry

Figure 4. Bar Chart of Survey Results

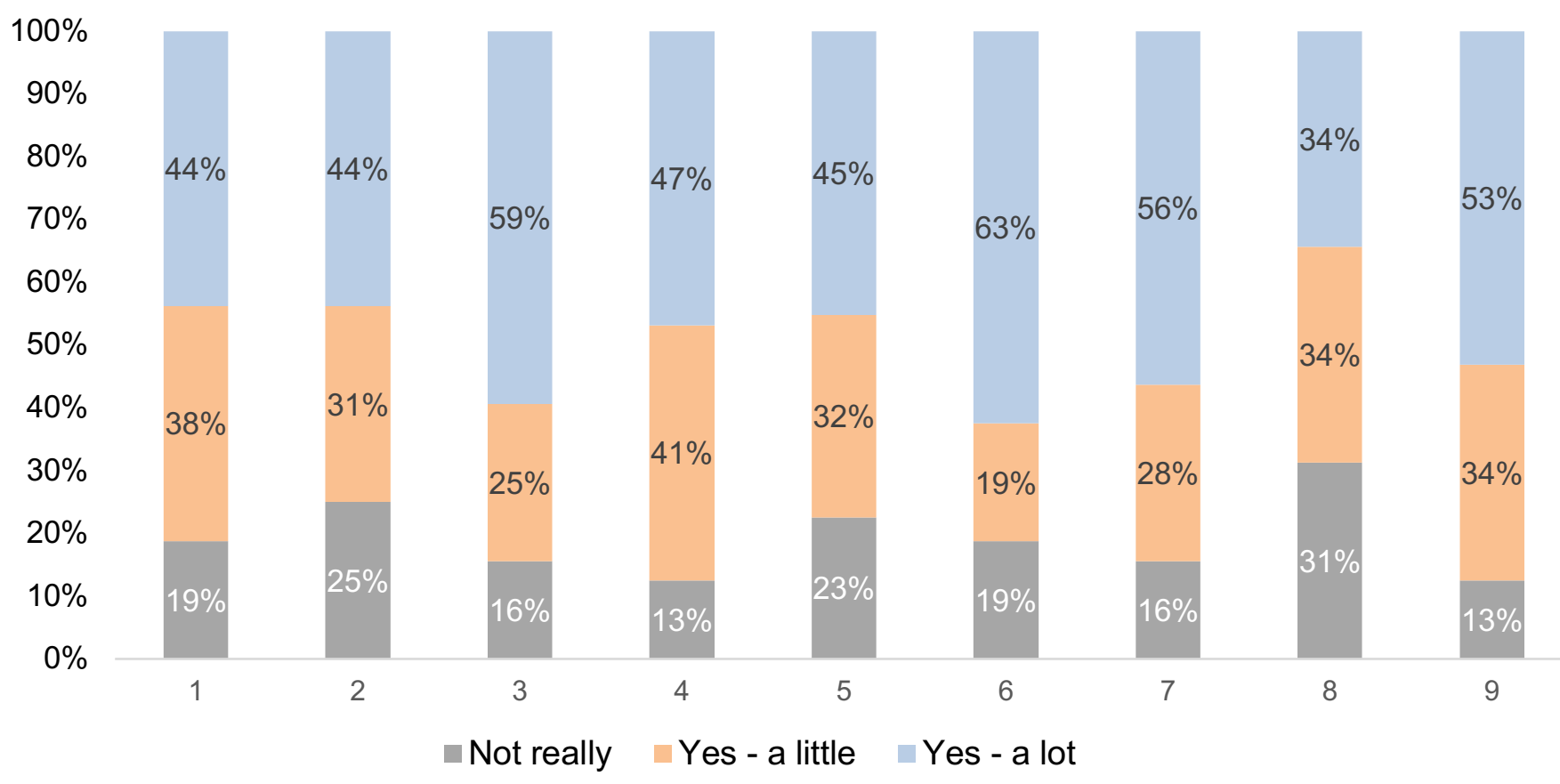

\section{Student Survey Questions}

(Survey to be read out loud)

1. You have been studying different animals as part of the PROGRAM this year. Please indicate what you know about your animal by filling in the chart below.

My animal is:

My animal eats:

My animal lives in:

Other animals that also live there are: 
A New Paradigm for STEM Learning and Identity in Young Immigrant and English Language Learners: Science Translation As Interdisciplinary, MultiModal Inquiry

My animal uses sound to:

The sound my animal makes is:

Dangers to my animal in the wild are:

2. Are there any other things that you can tell people about related to your

animal?

3. When scientists want to learn about an animal, they may do many things such as those listed below. Which of the things did you also do to learn about your animal?

\begin{tabular}{|c|c|}
\hline Watched it/Observed it & Talked with others about it \\
\hline $\begin{array}{c}\text { Looked up information about } \\
\text { it in a book }\end{array}$ & Recorded it \\
\hline $\begin{array}{c}\text { Wrote about it } \\
\text { Read about it }\end{array}$ & $\begin{array}{r}\text { Looked up information about } \\
\text { it on the Internet }\end{array}$ \\
\hline
\end{tabular}

4. Do you think you know more, about the same amount, or less about your animal than your friends who are not at UBEATS?

I know more

I know about the same amount

I know less

5. Has being a part of UBEATS:

\begin{tabular}{|l|l|l|l|}
\hline a) Increased your observation skills? & Yes, a lot & Yes, a little & Not really \\
\hline b) Increased your skills using technology? & Yes, a lot & Yes, a little & Not really \\
\hline
\end{tabular}


A New Paradigm for STEM Learning and Identity in Young Immigrant and English Language Learners: Science Translation As Interdisciplinary, MultiModal Inquiry

\begin{tabular}{|l|l|l|l|}
\hline c) Increased your interests in animals? & Yes, a lot & Yes, a little & Not really \\
\hline d) Increased your interest in nature? & Yes, a lot & Yes, a little & Not really \\
\hline $\begin{array}{l}\text { e) Increased your interest in science? } \\
\text { f) Helped you see that some scientists study } \\
\text { animals as a living? }\end{array}$ & Yes, a lot & Yes, a little & Not really \\
\hline $\begin{array}{l}\text { g) Helped you better understand what } \\
\text { scientists do? }\end{array}$ & Yes, a little & Not really \\
\hline $\begin{array}{l}\text { h) Changed your ideas about what scientists do? } \\
\text { i) } \begin{array}{l}\text { Made you think that being a scientist would } \\
\text { be fun? }\end{array}\end{array}$ Yes, a lot & Yes, a little & Not really \\
\hline
\end{tabular}

\section{Findings from Survey}

$$
\text { Spring, } 2016(n=32)
$$

Table 1: Number and Percent Providing Correct Responses

\begin{tabular}{lccc|cc} 
& $\begin{array}{c}\text { Gibbon } \\
(\mathrm{n}=14)\end{array}$ & $\begin{array}{c}\text { Penguin } \\
(\mathrm{n}=10)\end{array}$ & $\begin{array}{c}\text { Tiger } \\
(\mathrm{n}=8)\end{array}$ & $\begin{array}{c}\text { Total } \\
(\mathrm{n}=32)\end{array}$ & Percent \\
\hline My animal lives in: & $11 / 14$ & $9 / 10$ & $7 / 8$ & $\mathbf{2 7 / 3 2}$ & $84.4 \%$ \\
My animal eats: & $9 / 14$ & $9 / 10$ & $8 / 8$ & $\mathbf{2 6 / 3 2}$ & $81.3 \%$ \\
Dangers to my animal in the wild are: & $10 / 14$ & $8 / 10$ & $6 / 8$ & $\mathbf{2 4 / 3 2}$ & $75.0 \%$ \\
The sound my animal makes is: & $10 / 14$ & $6 / 10$ & $7 / 8$ & $\mathbf{2 3 / 3 2}$ & $71.9 \%$ \\
My animal uses sound to: & $6 / 14$ & $6 / 10$ & $8 / 8$ & $\mathbf{2 0 / 3 2}$ & $62.5 \%$ \\
Other animals that also live there are: & $3 / 14$ & $10 / 10$ & $6 / 8$ & $\mathbf{1 9 / 3 2}$ & $59.4 \%$ \\
Additional information about my animal: & $5 / 14$ & $5 / 10$ & $6 / 8$ & $\mathbf{1 6 / 3 2}$ & $50.0 \%$ \\
\hline$\quad$ Total: & $\mathbf{5 4 / 9 8}$ & $\mathbf{5 3 / 7 0}$ & $\mathbf{4 8 / 5 6}$ & $\mathbf{1 5 5 / 2 2 4}$ & $69.2 \%$
\end{tabular}




\section{A New Paradigm for STEM Learning and Identity in Young Immigrant and English Language Learners: Science Translation As Interdisciplinary, Multi- Modal Inquiry}

$$
\begin{array}{llll|l}
\text { Percent: } \quad 55.1 \% \quad 75.7 \% & 85.7 \% & 69.2 \%
\end{array}
$$

\section{Sample Responses}

Other animals that also live there: Penguin Seals, fish, shrimp, orcas, lions

My animal uses sound to: When baby is come, Talking to each other, Danger is coming, Trouble is coming, Communicate with their parents and friends, To find another tiger

The sound my animal makes: High and low pitch, A loud sound, Donkey sound, Owl sound, Roar, Chuffing

Dangers to my animal in the wild are: People because they cut the trees, People hunting them, Whale, Leopard seals, orca, and sharks, Lions

Additional information about my animal: A lot of people think the gibbon is a monkey but it is not because gibbons don't have tails; They look like little real kids. They eat using their hands. They climb trees; Brown fur, they have families, live in zoos; The mom and dad take turns taking care of the baby while one parents searches for food; I can tell them that penguins are very protective creatures, and they use guarding and going to find food strategies; They climb trees; My animal runs from danger or hides; They are very good. They like to eat meat and chicken.

\section{Figures 5a, b, c. PROGRAM Participant Demographics}

a. Country of Origin

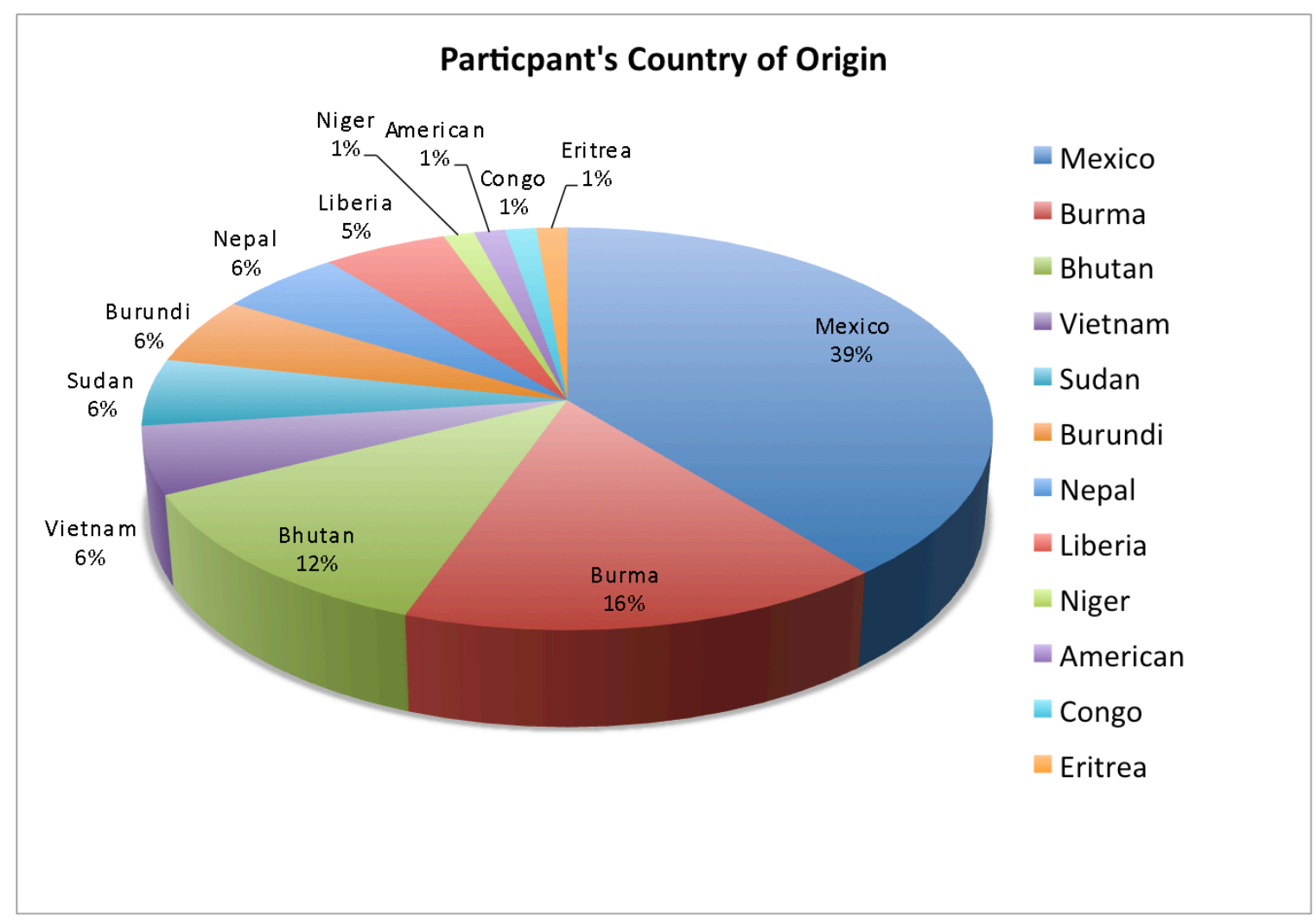


A New Paradigm for STEM Learning and Identity in Young Immigrant and English Language Learners: Science Translation As Interdisciplinary, MultiModal Inquiry

b. Gender

\section{Participant by Gender}

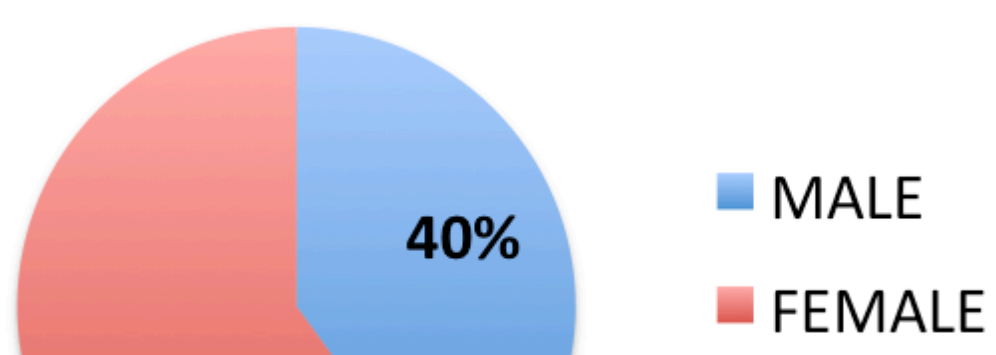

$60 \%$

c. Grade Level

\section{Participants by Grade Level}

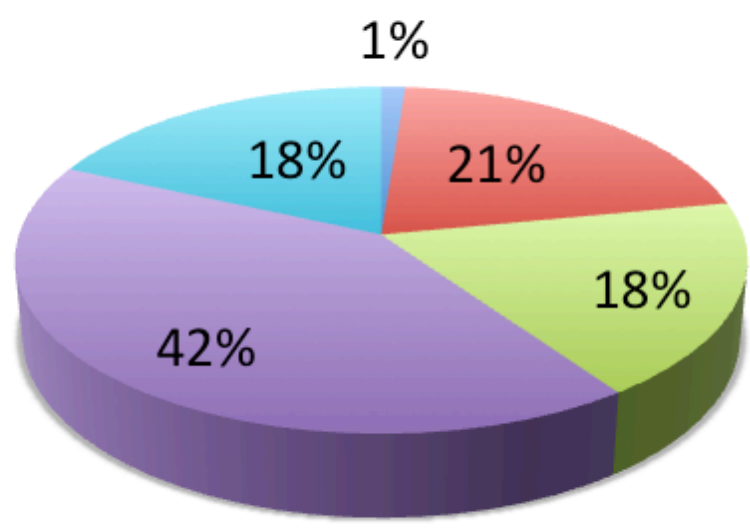

Third Grade

- Fourth Grade

Fifth Grade

Sixth Grade

Seventh Grade 